\title{
Maquet III procedure: what remains after initial complications - long-term results
}

\author{
Fernando Fonseca ${ }^{1,2^{*}}$, João Pedro Oliveira ${ }^{1,2}$ and Pinho Marques ${ }^{1,2}$
}

\begin{abstract}
Background: Maquet III procedure, unloved due to its complications (2\% to 59\%), has been progressively abandoned. At long-term follow-up, what happens to patients with complications that exceeded the initial ones (Acta Orthop Scand 60:20, 1989)? We retrospectively studied patients who were submitted to Maquet III procedure, by functional and radiologic long-term outcomes, in order to determine if this surgery has or has not fulfilled its initially proposed objectives. From 1970 to 1991, 116 patients benefit from the Maquet III procedure. From this, we were able to review in 2011, 23 patients (25 knees) who went through a single Maquet III procedure. Of these patients, 52\% were males. Age at surgery was $39.7 \pm 11.4$, with a postoperative follow-up of $27.2 \pm 3.1$ years.
\end{abstract}

Methods: A questionnaire has been prepared for collecting data, and it has been supplemented by clinical records. We evaluated the preoperative complaints, postoperative complications, and range of motion during the recovery time, as well as the postoperative pain-absence period. All patients underwent an objective assessment using the visual analog scale (VAS) at rest and activity, and the Kujala patellofemoral scoring system. A radiological assessment was also made in order to evaluate the arthrosis degree. The bicondylo-patellar angle described by Delgado-Martins (Arch Orthop Traumat Surg 96:303-304, 1980) was used to measure patellar tilt, and the Caton-Deschamps index to calculate the patellar height.

Results: Only one knee had benefited from a total knee arthroplasty (20 years after the Maquet III procedure). Preoperative complains were mainly anterior knee pain, crepitus, and patellar instability. Nowadays, 10 patients (40\%) still are pain free. Others had an average period without pain of $19.1 \pm 6.1$ years. VAS at rest was $1.7 \pm 0.7$ and in activity $4.4 \pm 3.0$. KPS was $61.9 \pm 22.3$ points. X-ray shows that $40 \%$ had a Kellgren-Lawrence grade of 1 at the patellofemoral joint.

Conclusion: Maquet proposed this technique for knee-pain relief, maintenance of the knee range of motion, and for slowly progressive osteoarthritic development. Viewed in a dispassionately way, we could notice that the initial objectives of this procedure were completely achieved. A part of $80 \%$ of the initial population was lost during follow-up, which may compromise the conclusions, perhaps, it is time to reflect again on this solution, so unloved by so many.

Keywords: Maquet III, Advancing anterior osteotomy of the anterior tibial tuberosity, Patellofemoral osteoarthritis, Long-term treatment

\footnotetext{
* Correspondence: pereirafonseca@gmail.com

${ }^{1}$ University Clinic of Orthopedics, Faculty of Medicine, University of Coimbra, Coimbra, Portugal

${ }^{2}$ Orthopedic Department, Centro Hospitalar e Universitário de Coimbra, Praceta Mota Pinto, 3000, Coimbra, Portugal
}

\section{Ciomed Central}

(c) 2013 Fonseca et al.; licensee BioMed Central Ltd. This is an Open Access article distributed under the terms of the Creative Commons Attribution License (http://creativecommons.org/licenses/by/2.0), which permits unrestricted use, distribution, and reproduction in any medium, provided the original work is properly cited. 


\section{Background}

Isolated patellofemoral osteoarthritis is rare, being present in $3.8 \%$ of the osteoarthritic knees [1,2]. Among the causes of chondromalacia and/or patellofemoral osteoarthritis are primary osteoarthritis without trauma history (49\%), recurrent patellar instability (33\%), chondrocalcinosis (9\%), and trauma history (9\%) [3].

Ideal treatment for chondromalacia and/or patellofemoral osteoarthritis on younger patients still remains unknown and a controversial topic. Conservative treatment with rest, strengthening of the quadriceps femoralis muscle, and intake of nonsteroidal anti-inflammatory drugs is a successful treatment in a significant number of patients $[1,4]$.

When conservative treatment fails, a surgical approach may be the solution. Several surgical options have been proposed ranging from Pridie's holes [5] to a patellectomy (described by Bentley [4]) as a solution.

Maquet [6] proposed a 2- to $2.5-\mathrm{cm}$ advancing anterior osteotomy of the anterior tibial tuberosity (ATT) for cases of chondromalacia and/or patellofemoral osteoarthritis resistant to conservative treatment. The rationale of this procedure is to augment the angle degree between the patellar and quadriceps tendon, reducing patellofemoral pressure [7]. After an enthusiastic period, many researchers reported a high rate of complications, especially on the healing process, because of the pressure placed under the skin due to the advancement of ATT [8]. In an attempt to reduce this complication, Ferguson et al. [9] suggested a modified procedure, reducing the advance to $1.25 \mathrm{~cm}$.

The aim of this study is to evaluate the long-term results of the patients with osteoarthritis and/or patellofemoral chondromalacia, who underwent a single Maquet III osteotomy [10-13].

\section{Materials and methods}

All surgical records of the Orthopedic Department between 1970 and 1991 were reviewed. Patients (116) who underwent Maquet III procedure for the treatment of chondromalacia and/or patellofemoral osteoarthritis were found. Surgical procedures were performed by or under the supervision of one of the senior authors (PM). Of these patients $(n=116), 37$ had no record in the National Health Service; 29 cases, in spite of having records, do not had phone numbers for contact to make an interview, and 16 patients had already died. The other patients were contacted by telephone call and were invited for medical evaluation. Six refused because they were suffering from other severe diseases. The remaining patients accepted to come to our hospital, but only 23 were really present for clinical and radiological evaluation. Since two patients were bilaterally operated, we had included 25 knees in this evaluation.

For those who came to the hospital, we prepared a questionnaire to collect data for pain assessment with a visual analog scale (VAS), with the lowest score of 0 that corresponds to 'pain free' and highest of 10 which means 'intolerable pain'. The patients were asked to mark at the line a point that corresponded to the exact level of pain they experienced currently at rest and a point that corresponded to the exact level of pain during daily life activities (DLA). For correlation, we use the Cox assessment scale [14] and the Kujala patellofemoral scoring system [15]. Free-pain period was registered as well as the range of motion.

Additionally, a radiographic study of the knee was made: antero-posterior view with a profile at $30^{\circ}$ of flexion and sky view of patella at $30^{\circ}$ of flexion. On radiographic evaluation, we tried to identify the existence of patellofemoral conflict, patellar subluxation, and osteoarthritis, classified according Kellgren-Lawrence criteria [16]. Patellar height was calculated using the Insall-Salvati index [17]. Bicondylo-femoral angle, described by DelgadoMartins [18], was utilized to measure the patellar tilt.

We considered an absolute surgery failure when patient is to undergo total knee arthroplasty (TKA) and a relative failure when patient relates pain that affects daily life activities. Patients' records were registered into a database and processed statistically; Chi-squared test was used for the categorical variables, and Student's $t$ test for the continuum variables. A $p$ value $<0.05$ was considered statistically significant. All the patients included in the study consented, and an approval from an ethics committee of our Hospital to retrieve the clinical data has been obtained.

\section{Results}

Pain was the most frequent preoperative complaint $(n=20$; $80 \%)$. The main reason for the surgery was patellofemoral osteoarthritis $(n=16 ; 64 \%)$, as shown in Table 1 .

All patients benefitted from an open knee arthrotomy with Maquet III procedure. Five patients benefitted from other complementary surgical procedures (Pridie's holes in two patients, medial meniscectomy in two, and sinovectomy in one). The mean time of hospitalization was $22.8 \pm 22.4$ days. Only $23.5 \%$ of the patients benefitted from physiotherapy procedures.

On the 2011 review, the mean postoperative follow-up was $27.2 \pm 3.1$ years with a mean pain-free time of 19.1 years. Tables 2 and 3 describe the results. Only one patient benefitted from a TKA 20 years after the primary surgery (4\%), and six had pain interfering with DLA (24\%). Twelve (48\%) of the patients are still pain free since surgery. For those with pain, VAS showed $76 \%$ of the patients had no pain at rest $(n=19)$; the remaining 6 patients were distributed between levels 2 and 3. With daily life activity, $76 \%(n=19)$ of the patients were also pain-free, $12 \%(n=3)$ had pain intensity between 3 and 4 , and $12 \%(n=3)$ with more than 5 . Cox score showed $68 \%$ $(n=17)$ as good/excellent, and $32 \%(n=8)$ as fair/poor. 
Table 1 Preoperative data

\begin{tabular}{ll}
\hline Demographic data & Number \\
\hline Age at surgery, mean (years) & $39.7 \pm 11.4$ \\
Age, mean (years) & $67.2 \pm 11.3$ \\
Sex, $n$ (\%) & $13(52)$ \\
Male & $12(48)$ \\
Female & \\
Knee involved, $n$ (\%) & $16(64)$ \\
Right & $9(36)$ \\
Left & \\
Former surgery, $n$ (\%) & $5(20)$ \\
Yes & $20(80)$ \\
No & \\
Main symptom, $n$ (\%) & $20(80)$ \\
Pain & $5(20)$ \\
Crepitus & \\
Diagnosis at surgery, $n$ (\%) & $16(64)$ \\
Patellofemoral osteoarthritis & $9(36)$ \\
Chondromalacia & $1(4)$ \\
Re-operation, $n$ (\%) & $1(4)$ \\
TKA & \\
Sinovectomia & \\
Others &
\end{tabular}

Kujala patellofemoral scoring revealed an average of $61.8 \pm 22.3$ points.

Based on the radiographic study, $48 \%(n=12)$ of the patients had an osteoarthritis grade of I-II, and $40 \%(n=10)$ had a grade of III-IV. The remaining three (12\%) patients still do not have patello-femoral osteoarthritis, independently of the long term follow-up. Patellar tilt measurement using the Delgado-Martins angle [18] shows that $40 \%$ ( $n=10)$ had a normal angle $\left(6^{\circ}\right.$ to $17^{\circ}$ at $30^{\circ}$ knee flexion), $4 \%(n=1)$ had more than $17^{\circ}$, and the remaining $56 \%$ $(n=14)$ had less than $6^{\circ}$. Figure 1 shows one excellent case.

The correlation between patello-femoral osteoarthritis and Kujala patellofemoral scoring shows a clinical degradation of quality of life as patients have a grade III or IV radiographic osteoarthritis, as shown in Table 4.

\section{Discussion}

Patellar chondromalacia was introduced in 1928 by Aleman [19] who described the degeneration of articular cartilage of the patella. Maquet described an original surgical procedure to treat these cases [6]. The treatment $[20,21]$ of chondromalacia and/or patellofemoral arthritis depends on the underlying cause and must be addressed based on that cause. Often, it involves non-surgical measures such as nonsteroidal anti-inflammatory drugs, strengthening of quadriceps femoralis, and lengthening
Table 2 Clinical data

\begin{tabular}{|c|c|}
\hline Postoperative data & Number \\
\hline Follow-up (mean in years) & $27.2 \pm 3.1$ \\
\hline Time without anterior-knee pain (mean in years) & $19.1 \pm 6.1$ \\
\hline \multicolumn{2}{|l|}{ Pain with DLA } \\
\hline Without pain & 12 \\
\hline Light & 7 \\
\hline Moderate with physical impact & 3 \\
\hline Sports practice & 3 \\
\hline \multicolumn{2}{|l|}{ VAS at rest $(\mathrm{cm})$} \\
\hline 0 & 19 \\
\hline 2 & 3 \\
\hline 3 & 3 \\
\hline \multicolumn{2}{|l|}{ VAS with ADL (cm) } \\
\hline 0 & 19 \\
\hline 3 & 2 \\
\hline 4 & 1 \\
\hline 7 & 3 \\
\hline \multicolumn{2}{|l|}{ COX score } \\
\hline Excellent & 9 \\
\hline Good & 8 \\
\hline Fair & 7 \\
\hline Poor & 1 \\
\hline Kujala patellofemoral scoring (mean) & $61.8 \pm 22.3$ \\
\hline
\end{tabular}

of hamstrings. Surgery is indicated for chronic pain when conservative treatment has failed. The procedures done were cartilage shaving with or without Pridie's drilling [5], Ficat procedure [13], lateral patellar facetectomy [13], patellar realignment, patellofemoral arthroplasty, and total knee replacement [1].

\section{Table 3 Radiologic findings}

\begin{tabular}{ll}
\hline & Number \\
\hline Patello-femoral osteoarthritis (Kellgren and Lawrence) & 3 \\
Absent & 10 \\
Grade I & 2 \\
Grade II & 5 \\
Grade III & 5 \\
Grade IV & \\
Patellar height (Insall-Salvati) & 8 \\
$<0.8$ & 17 \\
0.8 to 1.2 & \\
Patellar tilt (Delgado-Martins angle) & 14 \\
$<6^{\circ}$ & 10 \\
$6^{\circ}$ to $17^{\circ}$ & 1 \\
$>17^{\circ}$ &
\end{tabular}




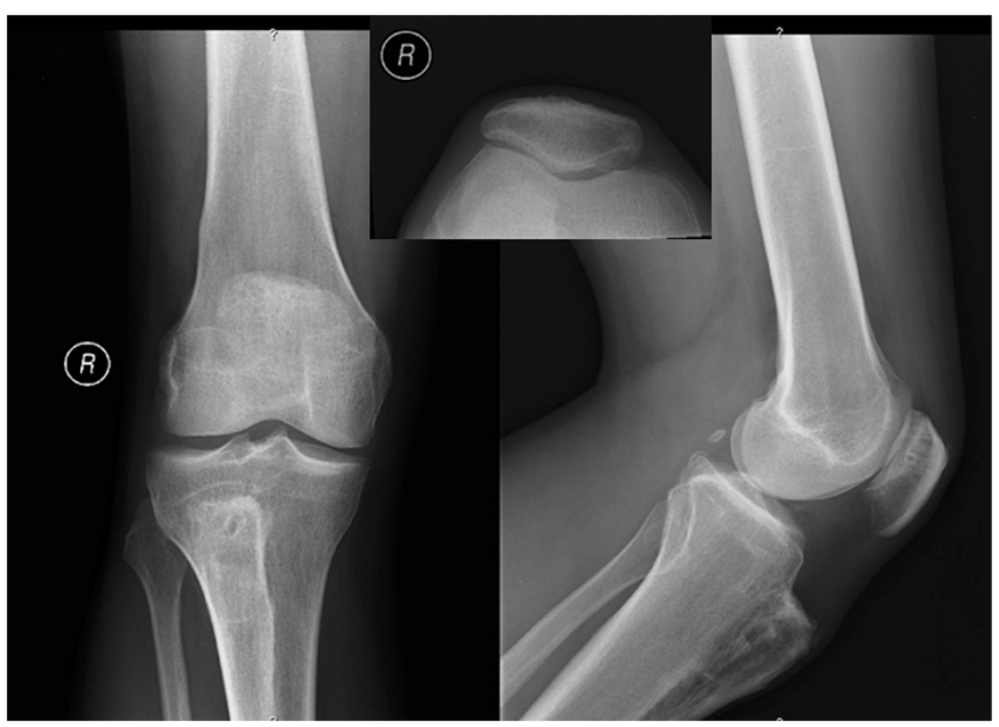

Figure 1 Male, 61 years; excellent Cox score and KPS of 98.

Maquet $[6,11]$ proposed the advancement of the anterior insertion of the patellar tendon at tibial tuberosity, reducing the pressure on the articular patellofemoral joint. Subsequent studies by Kaufer [22], Bandi and Brennwald [10], and Ferguson et al. [9] confirmed Maquet's data. In 1979, Maquet reported a reduction of $50 \%$ of the pressure on the patellofemoral joint with a $2 \mathrm{~cm}$ advancement of TTA [12]. This advancement was initially associated with a high rate of complications, especially on the healing process [8], as confirmed by Maquet's report (12\% of healing complications). Ferguson et al. [9] and Fulkerson and Shea [23] modified the original technique, limiting the elevation to $1.25 \mathrm{~cm}$, reporting only one case of healing problem on 184 patients. Mainly because of healing problems, this procedure has been progressively abandoned. Recent review articles documented a myriad of surgical approaches for this pathology [13], but these procedures do not have a long time follow-up.

What happens to patients with a Maquet III procedure 20 years or more after the surgery? As we know, there is no paper describing such long follow-up result. Maquet [11] reported 95\% good to excellent results ( $n=41$ patients), Ferguson et al. [9] 92\% ( $n=48$ patients), and Radin [24] 79\% ( $n=42$ patients).

Our study has more than 20 years of follow-up $(n=25)$, and even with this long term follow-up, we were able to review by clinical and radiological exams 23 of the 116 cases (19.8\%) registered in our hospital. Our long-term results

Table 4 Correlation of radiological findings versus KPS

\begin{tabular}{lccc}
\hline Patello-femoral osteoarthritis & Absent & Grade I/II & Grade III/IV \\
\hline Mean Kujala patellofemoral scoring & 81.0 & 64.7 & 51.7 \\
\hline
\end{tabular}

show only 1 (4\%) case of absolute surgery failure with $48 \%$ $(n=12)$ of excellent results (pain-free with DLA until now) with good Kujala patellofemoral scoring score. Apart from this, the remaining patients who complained of pain tolerate it and had good Cox score.

Have patellofemoral arthroplasty and other procedures resulted to such a performance at long term? Dejour and Allain [3] reported also good results but emphasized that the procedure does not stop the progression of osteoarthritis. We agree with this, but reviewing other procedures such as tibial tubercle medialization, the same authors report a long term development of osteoarthritis. Apart from skin and esthetic problems, patients had good outcomes 20 years or more after a Maquet procedure; this result proves that this procedure is better than other more popular ones.

Maquet III had three purposes: pain relief, maintenance of mobility, and prevention of osteoarthritis. The patients evaluated with a minimum of 20 years, after having pain relief for at least 15 years after surgery, also had good range of motion. Prevention of osteoarthritis was the only purpose that has not been totally achieved, but a delay of 15 years should be taken into account. Taking into consideration the loss of $80.2 \%$ of the patients during follow-up may compromise the final conclusions.

First of all, apart from skin complications, evidence supports that Maquet III is a reliable procedure with good results, better than other procedures which have results in less follow-up time. Second, in Maquet III procedure is important to prevent skin complications, as reported on a significant number of cases. Bandi and Brennwald [10] and Ferguson et al. [9] showed that 1 to $1.25 \mathrm{~cm}$ is enough to achieve the biomechanics effect 
proposed by Maquet. But with the advances and the current state of art at plastic surgery, it may be possible to prevent skin complications, avoiding high rates of complications.

\section{Conclusion}

Taking into account the loss of $80.2 \%$ of the initial population, in this long-term follow-up, we showed that patients who do not have skin problems after a single Maquet III procedure also have a long free-pain period with functional good outcomes. Avoiding skin problems, Maquet III procedure may be rehabilitated and rise again as a surgical option to treat isolated patello-femoral osteoarthritis.

\section{Competing interests}

The authors declare that they have no competing interests.

\section{Authors' contributions}

FF designed the study, reviewed the patients, wrote the paper, and supervised the research. JPO reviewed the patients and recorded the patients' data. PM wrote the paper and gave research advices. All authors read and approved the final manuscript.

Received: 31 July 2011 Accepted: 25 March 2013

Published: 1 May 2013

\section{References}

1. Insall J: Surgeny of the Knee. 2nd edition. Philadelphia: Churchill Livingstone; 1993.

2. Jackson RW: Etiology of chondromalacia patellae. Instr Course Lect 1976, 25:36.

3. Dejour D, Allain J: Histoire naturelle de l'arthrose femoro-patellaire isolee. Rev Chir Orthop 2004, 90(Suppl 5):1569-1S129.

4. Bentley G: Condromalacia patellae. J Bone Joint Surg 1970, 52(A):221.

5. Pridie KH: A method of resurfacing osteoarthritic knee joints. J Bone Joint Surg 1959, 41(B):618.

6. Maquet $\mathrm{P}:$ Un traitement biomecanique de l'arthrose femoro-patellaire: l'avancement du tendon rotulien. Rev Rhum Mal Osteoartic 1963, 30:779.

7. Hirsh DM, Reddy DK: Experience with Maquet anterior tibial tubercle advancement for patellofemoral arthralgia. Clin Orthop 1980, 148:136.

8. Radin EL: The Maquet procedure - anterior displacement of the tibial tubercle: indications, contraindications and precautions. Clin Orthop 1986, 213:241.

9. Ferguson $A B$, Brown TD, Fu FH, Rutkowsky R: Relief of patellofemoral contact stress by anterior displacement of the tibial tubercle. J Bone Joint Surg 1979, 61(A):159.

10. Bandi W, Brennwald J: The significance of femoro-patellar pressure in the pathogenesis and treatment of chondromalacia patellae and femoro-patellar arthrosis. In The Knee Joint. Edited by Ingerwersen OS. New York: Elsevier; 1974:63.

11. Maquet P: Advancement of the tibial tuberosity. Clin Orthop 1976, 115:225.

12. Maquet P: Mechanics and osteoarthritis of the patellofemoral joint. Clin Orthop 1979, 144:170.

13. Mihalko WM, Yaw D, Spang JT: Controversies and techniques in the surgical management of patella femoral arthritis. J Bone Joint Surg 2007, 89(A):2788-2802

14. Cox JS: Evaluation of the Roux-Elmslie-Trillat procedure for knee extensor realignment. Am J Sports Med 1982, 10(5):303-310.

15. Kujala UM, Jaakkola LH, Koshinen SK, Taimela S, Hurme M, Nelimarkka O: Scoring of patellofemoral disorders. Arthroscopy 1993, 9:159-163.

16. Kellgren JH, Lawrence JS: Radiologic assessment of osteoarthrosis. Ann Rheum Dis 1957, 16:494-502.

17. Insall J, Salvati E: Patella position in the normal knee joint. Radiology 1971, 101:101-104.

18. Delgado-Martins $\mathrm{H}$ : The bicondylo-patellar angle as a measure of patellar tilting. Arch Orthop Traumat Surg 1980, 96:303-304.
19. Aleman O: Chondromalacia post-traumatic patellae. Acta Chir Scand 1928, 63:149.

20. Canale ST, Beaty JH: Campbell's Operative Orthopaedics. 11th edition. Maryland Heights: Mosby; 2007.

21. Engebretsen L, Svenningsen S, Benum P: Advancement of the tibial tuberosity for patellar pain: a 5-year follow-up. Acta Orthop Scand 1989, 60:20

22. Kaufer H: Mechanical function of the patella. J Bone Joint Surg 1971, 53(A):1551.

23. Fulkerson JP, Shea KP: Disorders of patellofemoral alignment. J Bone Joint Surg 1990, 72A:1424.

24. Radin EL, Pan HQ: Long-term follow-up study on the Maquet procedure with special reference to the causes of failure. Clin Orthop Relat Res 1993, 290:253.

doi:10.1186/1749-799X-8-11

Cite this article as: Fonseca et al:: Maquet III procedure: what remains after initial complications - long-term results. Journal of Orthopaedic Surgery and Research 2013 8:11.

\section{Submit your next manuscript to BioMed Central and take full advantage of:}

- Convenient online submission

- Thorough peer review

- No space constraints or color figure charges

- Immediate publication on acceptance

- Inclusion in PubMed, CAS, Scopus and Google Scholar

- Research which is freely available for redistribution 